\title{
PANDEMIA Y PENSAMIENTO TEOLÓGICO
}

\section{Primeras palabras}

Fuimos sorprendidos por la pandemia, y con ella nos sorprendió una realidad presente pero invisibilizada una y otra vez, aquellos que siempre estuvieron en las periferias existenciales y espaciales lo estaban ahora de una manera más evidente. ¿Cómo pedirle a un sin techo que guarde el distanciamiento social? ¿Alguien pensó en las prostitutas? Incluso si es víctima de una red de trata de blancas, ¿quién pensó en las consecuencias del aislamiento para ellas? (Muchas, seguramente, se adecuaron a la situación entrando en un mundo de virtualidad). Se hablará, sin duda de planes económicos para aquellos más vulnerables, ¿en serio? ¿Cómo? ¿Para cuántos? ¿Pensamos en los desplazados? ¿Los migrantes? ¿Los refugiados?

Estas situaciones, y muchas otras que no enumeramos para no ser excesivos, las podemos contemplar desde un punto de vista sociológico, y está buena esa mirada. Sin embargo, de alguna manera reconocemos que hay otra mirada, la del creyente que busca en los acontecimientos y en las personas la huella de un Dios que no se hace el desentendido y que siempre está salvando, sanando, liberando.

Las siguientes líneas pretenden ser una mirada integradora de un creyente en torno a la situación actual y a algunas posibilidades que ofrece al pensamiento teológico. Siempre serán unas líneas incompletas, y siempre estarán necesitadas de una segunda lectura.

\section{Reflexiones generales}

La actual pandemia mundial que llamamos COVID19, representa una alteración tan significativa de los modos de relación humanos que abarca todas sus dimensiones, también en el campo de la reflexión y el pensamiento en general y del filosófico y teológico en particular.

Más allá del dato sanitario, es evidente que el modo de relacionarnos, como ya hemos apuntado, ha cambiado, se ha, por lo menos, alterado. En Argentina, donde me encuentro actualmente, ha significado no compartir el mate, por ejemplo, y si bien para algunos puede parecernos un hecho marginal 0 superficial, es un dato de gran importancia para quienes se comprenden desde la compartida del mate.

Este hecho es sólo una muestra, seguramente cada uno desde el lugar espacial y relacional donde se encuentra podrá dar muchos ejemplos de lo que tratamos de explicar: el cambio en un aspecto de la convivencia cotidiana afecta en lo más íntimo de la existencia humana. No sabemos si el cambio será significativo en términos de cultura, por eso prefiero llamarlo alteración, la permanencia e instalación de tal alteración no podemos evaluarla en estos tiempos presentes, pero es bueno estar atento a su curso. 
Por otra parte, nos encontramos con medidas de cuarentena y distanciamiento social que implicaron el cierre de templos, escuelas, restaurantes, bares, gimnasios, entre otros. Ello significó un nuevo modo de "encontrarse" que fue, básicamente el famoso "quedarse en casa". Con lo cual se instaló una cierta virtualidad, y diría que de manera forzosa. Si me preguntan, me atrevo a decir que si bien la virtualidad es bastante democrática, es también significativamente excluyente: basta pensar en el gran porcentaje de personas que no tienen acceso a la tecnología que se requiere. Luego están las decisiones personales/grupales políticas y propias del mercado: por qué se elige tal o cuál plataforma, con qué criterios elegimos una u otra red social, por qué son significativamente excluyentes las unas de las otras... el criterio de las mayorías, ¿es válido, aún asumiendo importantes riesgos de seguridad?

Hasta acá la situación general, a nivel de encuentro religioso, la pandemia ha significado la vivencia de todos estos elementos, sobre todo en lo que se refiere al culto comunitario y público. Por lo menos, para Occidente constituye una búsqueda de una relación con Dios más íntima, en el mejor de los casos, más familiar. La expresión religiosa del catolicismo, por lo menos, tiene un fuerte acento eclesial, y con ello queremos decir comunitario. No es que no se pueda expresar personalmente, pero su plenitud se encuentra en la familia y en la comunidad, que es siempre comunidad de familias.

La pandemia, me parece que ha resaltado los modos de pensar y relacionarnos como comunidad eclesial, para el que no está familiarizado, le puede parecer que todo en la Iglesia es monolítico, pero la realidad es que hay una gran diversidad de modos de comprensión, que van más allá de la facilonga catalogación de conservadores y progresistas. La pandemia, en esta línea, permite que uno subraye las propias creencias particulares y grupales, así, si estamos convencidos que la comunidad eclesial ha de asemejarse a un feudo, eso es lo que resaltaremos aún usando los medios audiovisuales. Los media, por sí mismos, no implican una nueva visión de la comunidad ni una eclesiología renovada, siempre serán medios, instrumentos, para transmitir un mensaje del modo que lo queremos transmitir.

\section{Posibles oportunidades que nos ofrece la situación actual}

Una primera oportunidad que se nos presenta, a nivel del pensamiento católico, por lo menos, es la posibilidad no sólo de reflexionar sobre la dimensión sacramental y litúrgica, la oración y el culto público, sino la necesaria actualización de la tal dimensión. Esto es: desde el Concilio Vaticano II ha pasado, por lo menos, medio siglo, en el cual se han dado cambios tan significativos que es imposible pretender que la vivencia litúrgico-sacramental pueda ser de la misma manera. Ya la pre-pandemia exigía esta reflexión transformadora, pero la pandemia la hace más evidente.

A la par de esta reflexión, hay otro tema que se hace mucho más presente en esta época, aunque ya viene de alguna manera andando desde hace un buen tiempo, se trata de los ministerios en general y de los ministerios ordenados en particular. Los antecedentes de esta reflexión tienen que ver con la concepción 
clerical y los abusos, de consciencia, sexuales y de poder, que se han derivado de la misma. La nueva normalidad, ¿qué ministerios requiere? ¿Cuál ha de ser la vivencia del ministerio ordenado en la pos-pandemia?

En tercer lugar, es claro que la pandemia nos ha llevado, en mayor o menor medida, a un cuestionamiento de Dios, la pregunta ¿dónde está Dios?, se hace particularmente incisiva en la actualidad. Sin embargo, hay que preguntarse por Dios mismo, a quién se le pregunta, ¿a una idea?, o ¿a una persona? ¿Cómo nos relacionamos con Dios? ¿Nuestra manera de relacionarnos con Dios, no será, más bien, idolátrica? ¿Estaremos siguiendo a Jesús o estamos estancados ante los ídolos que nosotros mismos hemos moldeado?

\title{
Conclusiones
}

Si bien la pandemia nos ofrece oportunidades, considero que la mayor de ellas es la búsqueda de nuevos caminos, no en plan individualista, sino en plan de construcción comunitaria, esta novedad de caminos no significa una renuncia a la tradición ni al magisterio, sino una profundización tal de la vivencia religiosa y de los contenidos de fe que nos permitan actualizarlos, apropiárnoslo de manera coherente y liberadora.

Por ello, la tarea del discípulo-misionero, del bautizado, en fin, del creyente, ha de estar signada, por una parte, en el encuentro con el Dios vivo y verdadero, con el Padre de Jesús que nos envía su Espíritu. Este encuentro es posibilitado en una vida de lectura, personal y comunitaria, de la Palabra y en la dimensión místico-litúrgica de la comunidad. Esta lectura orante de la Palabra debe no sólo iluminar la situación que vivimos, sino ayudarnos a una escucha sanante de la realidad. La persona de fe escucha a Dios no para condenar el mundo, sino para colaborar en su plan de salvación, de sanación, de liberación.

\author{
Víctor Argimiro Tarazona \\ vargimirot@gmail.com \\ Instituto de Investigación y Estudios Avanzados Koinonía \\ Extensión Argentina
}

